\title{
Editorial
}

\section{A New MDPI Proceedings Series Journal: Environmental Sciences Proceedings}

\author{
Environmental Sciences Proceedings Editorial Office
}

MDPI AG, St. Alban-Anlage 66, 4052 Basel, Switzerland; environsciproc@mdpi.com

Received: 18 May 2020; Accepted: 18 May 2020; Published: 4 June 2020

MDPI supports open academic communication in all its forms, through the publication of research articles as well as by supporting, organizing, and communicating outcomes from conferences, seminars, and other academic meetings. It is vital to have an open record of important academic discussions and, for this reason, we established Proceedings in 2017 with the aim of publishing the outputs of scholarly events. The journal has been extremely successful, and we have taken the decision to create a family of proceedings journals covering different subject areas. We are therefore pleased to announce the launch of Environmental Sciences Proceedings, Engineering Proceedings, Chemistry Proceedings, and Materials Proceedings. These journals will publish proceedings papers, extended abstracts, reports of meetings, and editorials related to scholarly events. To date, Proceedings has published more than 4700 such pieces and we look forward to expanding this number and broadening the scope with these new journals.

In launching Environmental Sciences Proceedings, MDPI is drawing on the strengths of journals such as the Journal of Environmental Research and Public Health, Environments, and Sustainability to address some of the most important questions of our age. What changes are happening to our planet and its habitat? What effect does human behavior have on our surroundings, and what practical measures can be taken? It combines MDPI's core principles of openness, fast communication of important research, and sustainability.

Anyone interested in contributing to an MDPI proceedings journal should contact the editorial office. We look forward to working with event organizers and committees on this important project. 